\title{
Calibrating SeaWinds and QuikSCAT scatterometers using natural land targets
}

David G. Long

david_long@byu.edu

Lucas B. Kunz

Follow this and additional works at: https://scholarsarchive.byu.edu/facpub

Part of the Electrical and Computer Engineering Commons

\section{Original Publication Citation}

Kunz, L. B., and D. G. Long. "Calibrating SeaWinds and QuikSCAT Scatterometers using Natural Land Targets." Geoscience and Remote Sensing Letters, IEEE 2.2 (25): 182-6

\section{BYU ScholarsArchive Citation}

Long, David G. and Kunz, Lucas B., "Calibrating SeaWinds and QuikSCAT scatterometers using natural land targets" (2005). Faculty Publications. 387.

https://scholarsarchive.byu.edu/facpub/387

This Peer-Reviewed Article is brought to you for free and open access by BYU ScholarsArchive. It has been accepted for inclusion in Faculty Publications by an authorized administrator of BYU ScholarsArchive. For more information, please contact ellen_amatangelo@byu.edu. 


\title{
Calibrating SeaWinds and QuikSCAT Scatterometers Using Natural Land Targets
}

\author{
Lukas B. Kunz, Student Member, IEEE, and David G. Long, Senior Member, IEEE
}

\begin{abstract}
The SeaWinds-on-QuikSCAT (QuikSCAT) and SeaWinds-on-ADEOS-2 (SeaWinds) scatterometers measure the normalized radar backscatter $\left(\sigma^{\circ}\right)$ of the earth's surface. These identical radar sensors are on different spaceborne platforms in similar orbits. QuikSCAT and SeaWinds data are used to infer near-surface wind vectors, polar sea-ice extent, polar-ice melt events, etc. In order to verify the relative calibration of these sensors, a simple cross calibration based on land backscatter measurements is performed. A first-order polynomial model is used to remove the incidence angle dependence of $\sigma^{\circ}$ for selected regions of the Amazon rainforest and the Sahara Desert. It is shown that the two sensors are well-calibrated to each other and require no bias corrections. Additionally, evidence of a diurnal cycle in the Amazon rainforest backscatter is given.
\end{abstract}

Index Terms-Amazon forest, calibration, QuikSCAT, radar cross section, SeaWinds.

\section{INTRODUCTION}

$\mathbf{T}$ HE NORMALIZED radar backscatter $\left(\sigma^{o}\right)$ measurements collected by spaceborne scatterometers are used in numerous areas of remote sensing research. Inferring geophysical phenomena from this data relies upon the accuracy of the measurements. Postlaunch calibration and verification is used to ensure that scatterometer measurements are properly calibrated for such applications.

Recently, two SeaWinds instruments were flown simultaneously, one (referred to as QuikSCAT) on the QuikSCAT satellite and the other (referred to as SeaWinds) on the Advanced Earth Observation Satellite 2 (ADEOS-II). The tandem mission of the QuikSCAT and SeaWinds instruments yields a particularly useful dataset, since the two sensors have identical specifications and follow nearly the same orbital path. This data provides high spatial and temporal resolution measurements with increased insight into the diurnal cycle. Proper cross calibration of these instruments is essential in order to maximize the utility of the data.

Tropical rainforests have traditionally been used to calibrate scatterometers [1]-[4]. The Amazon rainforest covers a large spatially homogeneous area and exhibits little seasonal or azimuthal variation. It can effectively be used for scatterometer calibration to within a limit of $\pm 0.15 \mathrm{~dB}$ for a relative calibration method designed to ensure intrasensor antenna consistency [2]. However, some concern has been noted over possible time-of-day effects relating to the diurnal cycle [1], [2],

Manuscript received July 22, 2004; revised November 20, 2004. This work was supported by the National Aeronautics and Space Administration.

The authors are with the Microwave Earth Remote Sensing Laboratory, Brigham Young University, Provo, UT 84602 USA (e-mail: long@ee.byu.edu).

Digital Object Identifier 10.1109/LGRS.2004.842468
[5]. As a result, ocean-based techniques were used to individually calibrate QuikSCAT and SeaWinds [6], with only a limited land-based study for QuikSCAT calibration [7]. Here, we desire to verify the relative cross calibration of the two SeaWinds sensors using land regions. We consider two regions: the Amazon rainforest and the Sahara Desert.

The normalized radar backscatter for a given target varies with time, azimuth, incidence angle, and polarization. Suitable targets for calibration have an isotropic radar response (i.e., independent of azimuth) and are temporally stable [2]. Ideally, such targets exhibit only incidence angle dependence in the $\sigma^{o}$ response. Previous scatterometers measured $\sigma^{o}$ over wide ranges. However, QuikSCAT and SeaWinds observe $\sigma^{\circ}$ at narrow incidence angle ranges. As discussed in [7], the absolute calibration of QuikSCAT is consistent with NSCAT and prior sensors.

Following Long and Skouson [2], locations in the Amazon and the Sahara with a radar response within $\pm 0.5 \mathrm{~dB}$ of a typical vertically polarized $\sigma^{\circ}$ value $(-9.45 \mathrm{~dB}$ in the Amazon and -28.5 in the Sahara at $54^{\circ}$ incidence angle) from the respective regions are used in the calibration verification. For the Amazon, the area considered is a neighborhood of radius $\sim 1200 \mathrm{~km}$ centered at $3^{\circ} \mathrm{S}, 61^{\circ} \mathrm{W}$, and the Sahara Desert site is centered at $20^{\circ} \mathrm{N}, 14^{\circ} \mathrm{E}$ with a radius of $\sim 700 \mathrm{~km}$. Spatial masks for these areas are created as described by Zec et al. [4] using a threeweek window of data starting at Julian Day (JD) 169 (see Fig. 1). These land targets lie in the same latitudinal band and offer different insights into the diurnal cycle. No diurnal variation is expected in the Sahara Desert. The masks include pixels meeting the selection criteria for any pass during the period except that in creating the Amazon mask the ascending QuikSCAT measurements were not used. The results are relatively insensitive to the mask.

In this letter, a cross-calibration analysis is performed between the QuikSCAT and SeaWinds scatterometers using Amazon and Sahara data. The data from JD 169-224, 2003 are used and measurements collected by each antenna are adjusted for $\sigma^{o}$ incidence angle dependence. Corrected results are presented for each antenna beam and each sensor for the two regions. Additional evidence of the variation in the Amazon's radar response due to the diurnal cycle is also given. Section II details the operating characteristics of the instruments. Section III presents the calibration method, and Section IV contains results. Conclusions are provided in Section V.

\section{QUIKSCAT AND SEAWINDS SCATTEROMETERS}

The QuikSCAT scatterometer was launched in June 1999 and operates at $13.6 \mathrm{GHz}$ (Ku-band) with two scanning pencil-beam antennas. The horizonatal polarization $(\mathrm{H}-\mathrm{pol})$ inner beam has a 


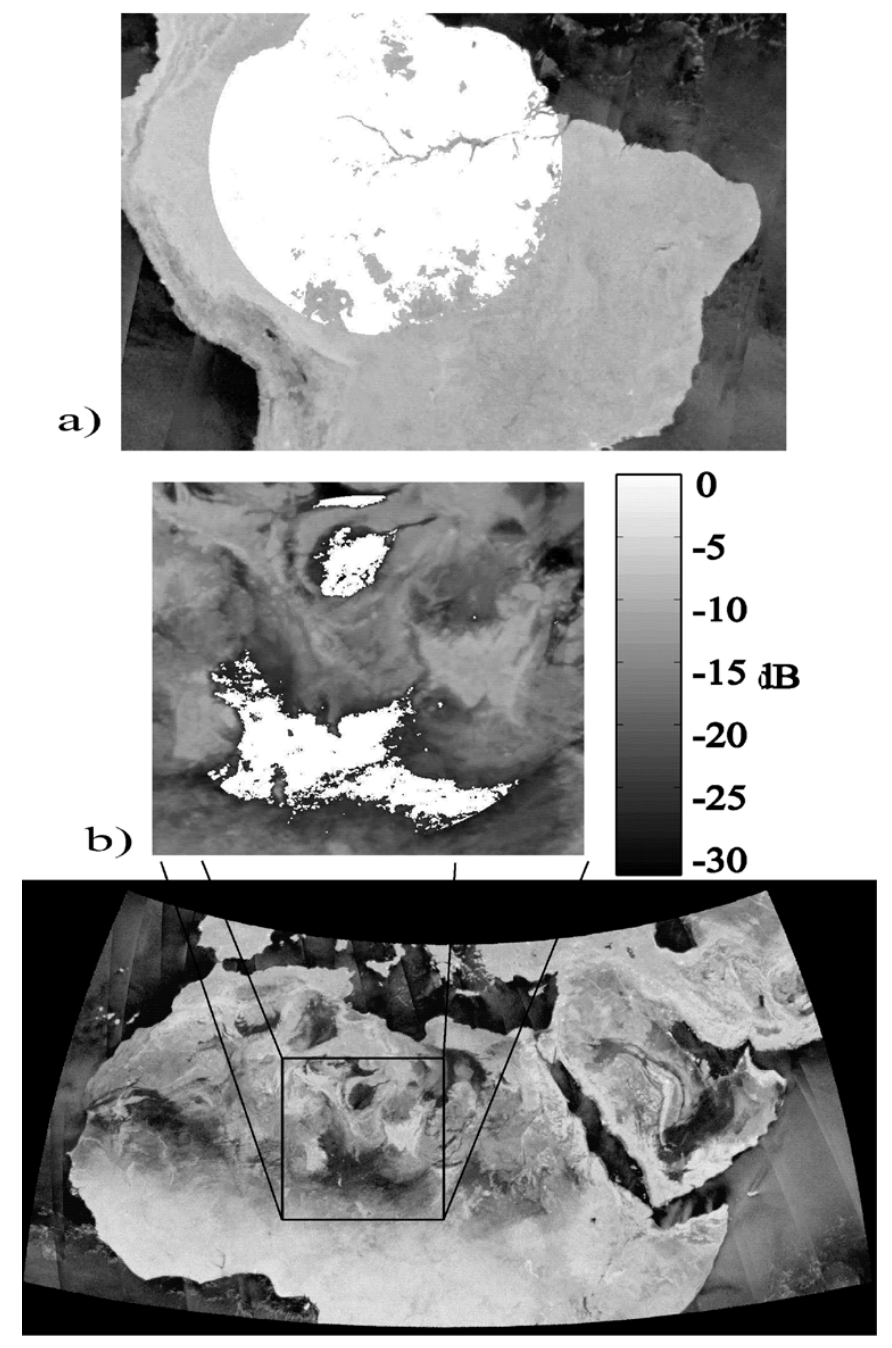

Fig. 1. Selected homogeneous regions from (a) the Amazon and (b) the Sahara. The white pixels indicate the masked areas used in the analysis.

nominal incidence angle of $46^{\circ}$ and traces out a $1400-\mathrm{km}$-wide swath, while the vertical polarization (V-pol) outer beam has a nominal incidence angle of $54^{\circ}$ and traces out a $1800-\mathrm{km}$-wide swath. Along its polar orbit, QuikSCAT covers $\sim 92 \%$ of the earth's surface daily [8]. Two types of $\sigma^{\circ}$ measurements are collected: "egg" and "slice" observations. Egg measurements have a nominal resolution of $25 \mathrm{~km}$, while slice measurements are noisier and have finer resolution [8], [9]. The range of nominal incidence angles reported for eggs is also smaller than for slices. The SeaWinds scatterometer was launched in December 2002 and has identical specifications to QuikSCAT. It operated until October 24, 2003 when the spacecraft power system failed. Data from the abbreviated SeaWinds mission is available from JD 100-297, 2003.

Although these sensors are identical, their respective platforms have different characteristics: ADEOS-II uses geocentric nadir pointing, while QuikSCAT uses geodetic nadir pointing and has very stable attitude. Due to the earth's ellipticity, geocentric pointing results in a larger variation in incidence angles for SeaWinds than QuikSCAT, as is evident in Fig. 2.

SeaWinds trails QuikSCAT along its orbital path and crosses the equator on ascending and descending passes approximately
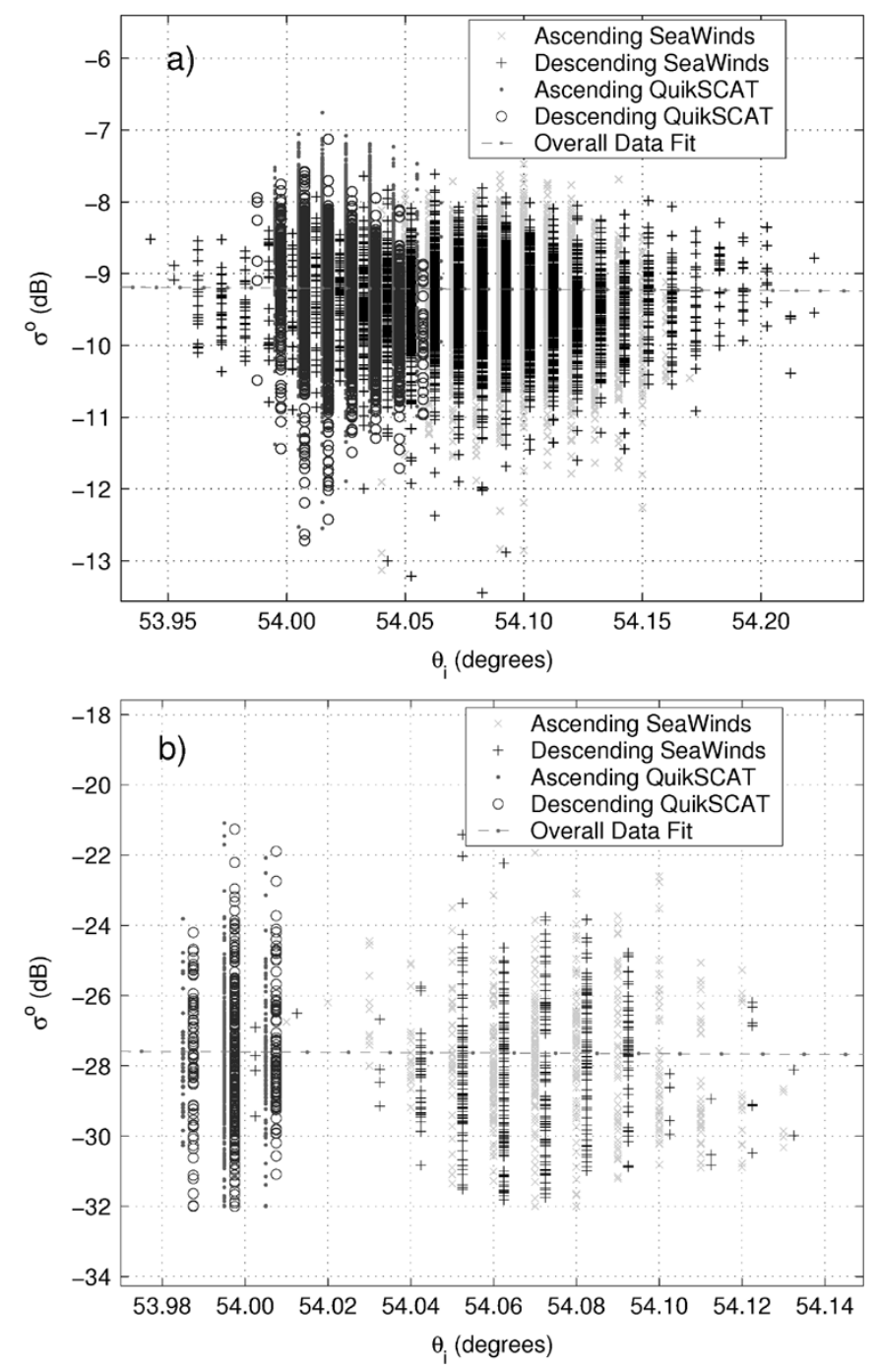

Fig. 2. Plots of uncorrected V-pol $\sigma^{\circ}$ versus $\theta_{i}$ pixel values from egg SIR imagery for the (a) Amazon and (b) Sahara masked regions for JD 169-224, 2004. Due to the number of points, only a small fraction of the data is shown.

$4 \mathrm{~h}$ after QuikSCAT. Fig. 3 is a histogram of the time-of-day associated with each backscatter measurement made by both sensors during ascending and descending passes over a four-day period during JD 139-142, 2003. The orbit paths for the two satellites repeat every four days. The ascending passes of QuikSCAT typically observe the Amazon region from 6-7 A.M. local time, while its descending passes occur from 6-7 P.M. The ascending and descending passes of SeaWinds cross over the Amazon from 10-11 A.M. and 10-11 P.M. local time, respectively (see Fig. 3). This temporal sampling over the rainforest is key in observing diurnal variation of the backscatter.

All previous calibration and verification methods have used raw $\sigma^{\circ}$ measurements. However, here we use data images generated via the scatterometer image reconstruction (SIR) algorithm [10] available from the Scatterometer Climate Record Pathfinder (http://www.scp.byu.edu). Using the algorithm, we combine measurements from different orbits for each sensor during a four-day span to create separate ascending and descending data images for the Amazon and northern Africa. These four-day composite images offer complete coverage of 


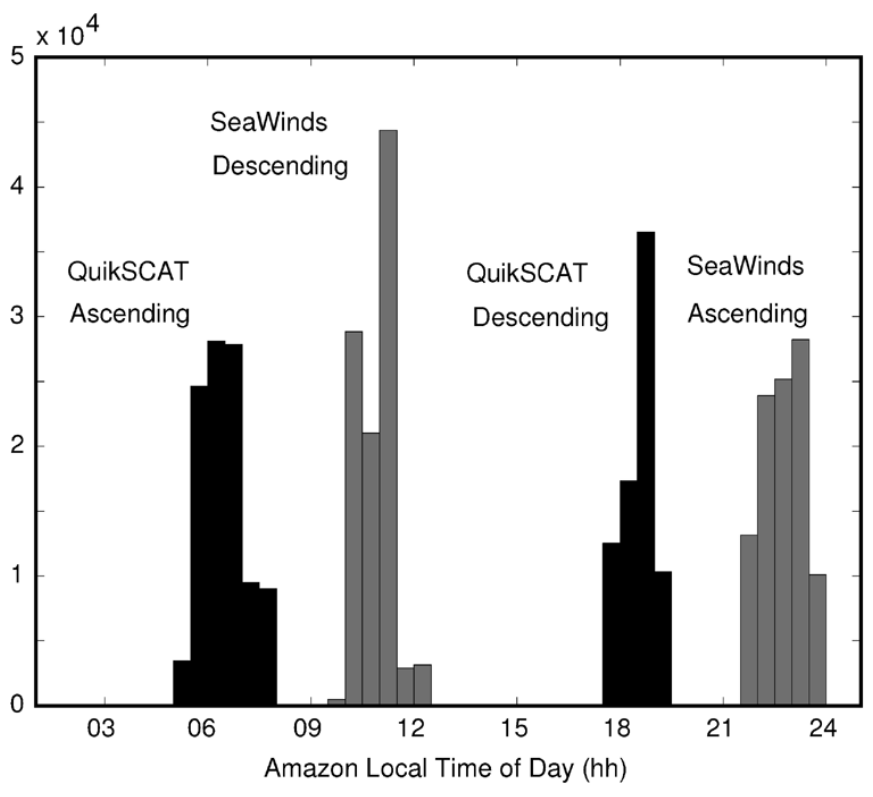

Fig. 3. Histogram of local times of day for backscatter measurements from all passes of both sensors during a four-day orbit cycle.

these regions and increased spatial resolution. Due to the orbit and swath geometry, images created from data collected during a given pass type (ascending or descending) for a given sensor are collected at the same local time-of-day, e.g., 6-7 A.M. for the ascending QuikSCAT Amazon.

The SIR image products have a pixel resolution of $2.225 \mathrm{~km} /$ pixel for "slice" images and $4.45 \mathrm{~km} / \mathrm{pixel}$ for "egg" images. Slice and egg images are separately considered, but only results from the slice corrections are shown, since there is no significant difference in the results from the egg analysis. In processing the images, the average incidence angle of the measurements included in each pixel is computed and used for incidence angle correction. Over the Amazon, the standard deviation of the pixel-averaged slice incidence angle is $0.013^{\circ}$, $0.013^{\circ}, 0.021^{\circ}$, and $0.034^{\circ}$ for the ascending and descending passes of QuikSCAT and SeaWinds, respectively.

\section{INCIDENCE ANGLE CORRECTION}

A $p$-order polynomial incidence angle response model [2] was used by Zec et al. [4] for the calibration of the NASA Scatterometer (NSCAT), which also operated in Ku-band. The results from the NSCAT calibration yielded very small higher order polynomial coefficients; therefore, a simple first-order polynomial model is used for calibration of QuikSCAT and SeaWinds, which have narrow (typically less than $1^{\circ}$ for a given beam) incidence angle ranges.

The model for the incidence angle dependence of $\sigma^{o}$ in decibels is

$$
\sigma_{b i}^{o}=A+B\left(\bar{\Theta}_{b}-\theta_{b i}\right)
$$

where $i$ is the pixel index of the SIR image for antenna beam $b$, $A$ is the corrected backscatter value in decibels, $B$ is the linear dependence on incidence angle in decibels per degree, $\bar{\Theta}_{b}$ is the nominal incidence angle for each beam $\left(54^{\circ}\right.$ for $\mathrm{V}$-pol and $46^{\circ}$
TABLE I

INCIDENCE ANGLE DEPENDENCE COEFFICIENTS ( $B$ IN DECIBELS PER DEGREE) FOR EACH REGION POLARIZATION AND RESOLUTION

\begin{tabular}{l|l|l|l}
\hline Polarization & Resolution & Amazon & Sahara \\
\hline \hline horizontal & slice & 0.169 & 0.584 \\
& egg & 0.169 & 0.573 \\
\hline vertical & slice & 0.172 & 0.521 \\
& egg & 0.170 & 0.511 \\
\hline
\end{tabular}

for $\mathrm{H}-\mathrm{pol}), \theta_{b i}$ is the measurement incidence angle in degrees, and $\sigma_{b i}^{o}$ is the observed backscatter value in decibels.

The incidence angle dependence coefficient $B$ is calculated as the slope of the linear least squares fit to the combined data from all passes from both instruments over the reference region. Fig. 2 illustrates the incidence angle dependence of the backscatter values over one four-day period, while Table I provides the calculated $B$ values over the full mission.

At mid to high incidence angles, the backscatter in the Amazon rainforest consists primarily of volume scattering, with some rough-surface scattering. Since QuikSCAT and SeaWinds measure backscatter at large incidence angles, the data recorded by these scatterometers exhibit only limited incidence angle dependence. At large incidence angles, backscatter in the Sahara Desert is characterized by specular scattering and some rough-surface scattering. Thus, the backscatter dependence on incidence angle is very strong. The $B$ values of Table I indicate that at high incidence angles the difference in the incidence angle dependence between polarizations for QuikSCAT and SeaWinds is also more pronounced over the desert. QuikSCAT and SeaWinds Amazon $B$ values are similar to Seasat [1], [2] and NSCAT [4] values.

Satake and Hanado [5] also observed a similar difference in incidence angle dependence between rainforests and deserts at low incidence angles. They used backscatter measurements from the Tropical Rainfall Measuring Mission (TRMM) Precipitation Radar (PR) to analyze the incidence angle dependence of $\sigma^{\circ}$ over small regions in the Amazon rainforest and the Libyan desert. In contrast to the nominal QuikSCAT and SeaWinds incidence angles of $46^{\circ}$ and $54^{\circ}$, the Ku-band TRMM PR scans incidence angles between $0^{\circ}$ and $17^{\circ}$ [5].

\section{CRoss-Calibration Analysis Results}

Significant temporal differences between the Amazon and Sahara regions are observed. For the Amazon, the ascending passes of QuikSCAT observe significantly higher backscatter values than the descending passes and are higher than both passes of SeaWinds (see Fig. 4). This variation is not observed for the Sahara.

\section{A. Amazon}

The ascending passes of QuikSCAT measure the Amazon's radar response in the early morning hours (see Fig. 3) when dew is present on the rainforest foliage. The increased backscatter at this time is consistent with previous observations of the Amazon [1], [2], [4], [5]. At low incidence angles, Satake and Hanado [5] observed a difference in $\sigma^{\circ}$ of $\sim 0.5 \mathrm{~dB}$ between the maximum backscatter from 6-7 A.M. local time and the 


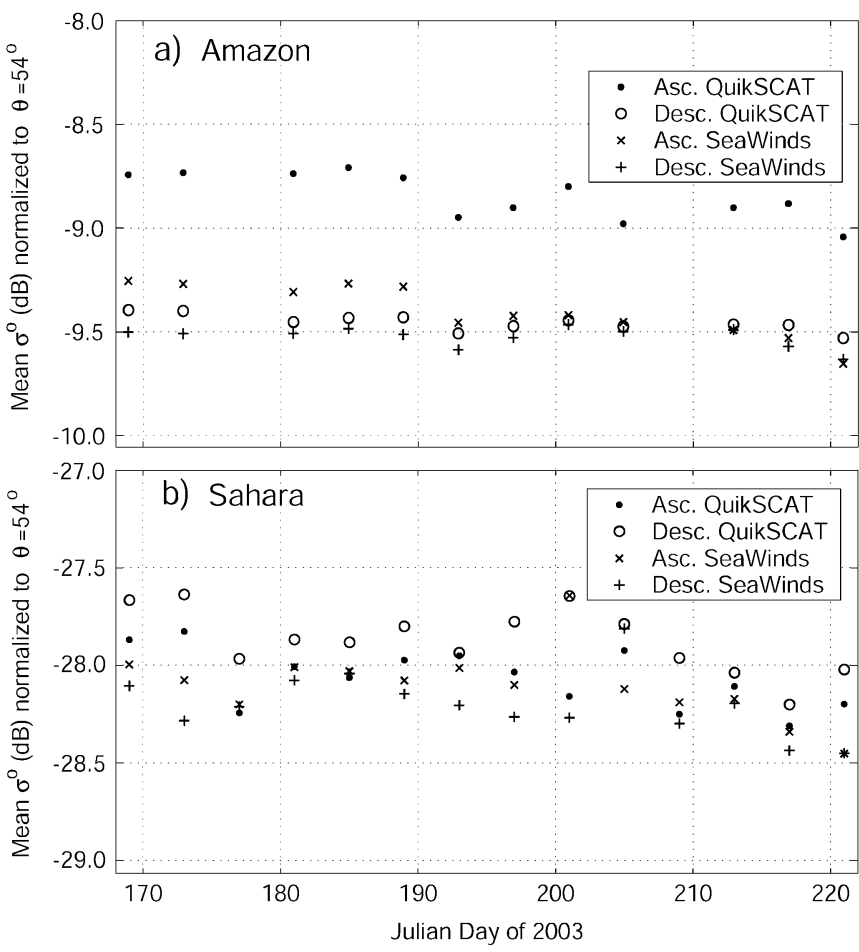

Fig. 4. Mean incidence-angle-corrected backscatter time-series for incidence-angle-corrected V-pol slice $\sigma^{\circ}$ for JD 169-224, 2003 in the masked (a) Amazon and (b) Sahara regions. Note the clear bias due to the diurnal cycle between the ascending QuikSCAT values and the other measurements for the Amazon.

TABLE II

V-Pol Slice Statistics for Each Region. H-Pol and EgG Statistics ARE Similar. THE MEAN $(M\{\mu\})$ AND STANDARD DEVIATION $(\operatorname{SD}\{\mu\})$ OF THE DaIly Regional MEAN $\mu$ OF THE MASKED SIR IMAGE VALUES AND THE MEAN $\left(m_{\mathrm{SD}}\right)$ OF THE DAILY STANDARD DEVIATION OF the Masked SIR IMage Values. Calculations ARe Made iN LOG SPACE. RESUlTS ARE IN DECIBELS

\begin{tabular}{l|l||c|c|c||c|c|c}
\hline \multirow{2}{*}{ Sensor } & Pass & $M\{\mu\}$ & $S D\{\mu\}$ & $m_{S D}$ & $M\{\mu\}$ & $S D\{\mu\}$ & $m_{S D}$ \\
\hline \hline QuikSCAT & asc & -8.85 & 0.112 & 0.60 & -28.07 & 0.151 & 1.80 \\
& des & -9.46 & 0.050 & 0.51 & -27.87 & 0.164 & 1.85 \\
\hline SeaWinds & asc & -9.40 & 0.126 & 0.56 & -28.10 & 0.186 & 1.87 \\
& des & -9.52 & 0.048 & 0.49 & -28.20 & 0.163 & 1.77 \\
\hline
\end{tabular}

minimum backscatter from 6-7 P.M. local time at low incidence angles. At the higher incidence angle of QuikSCAT and SeaWinds, we observe a difference of $\sim 0.6 \mathrm{~dB}$ between the morning and other observations throughout the day in the incidence angle corrected data (Fig. 4). The time averaged sensor values are within $\sim \pm 0.05$ for afternoon and evening passes (see Table II).

The local time-of-day sampling provided by the combined data from QuikSCAT and SeaWinds enables us to resolve the diurnal cycle. In Fig. 5 the mean incidence angle corrected values are plotted as a function of local time-of-day. Coupled with the observations of the Sahara by Satake and Hando [5], we conclude that the variations observed during the day in the Amazon are due to the diurnal moisture cycle, resolving previous speculations first articulated in [1].

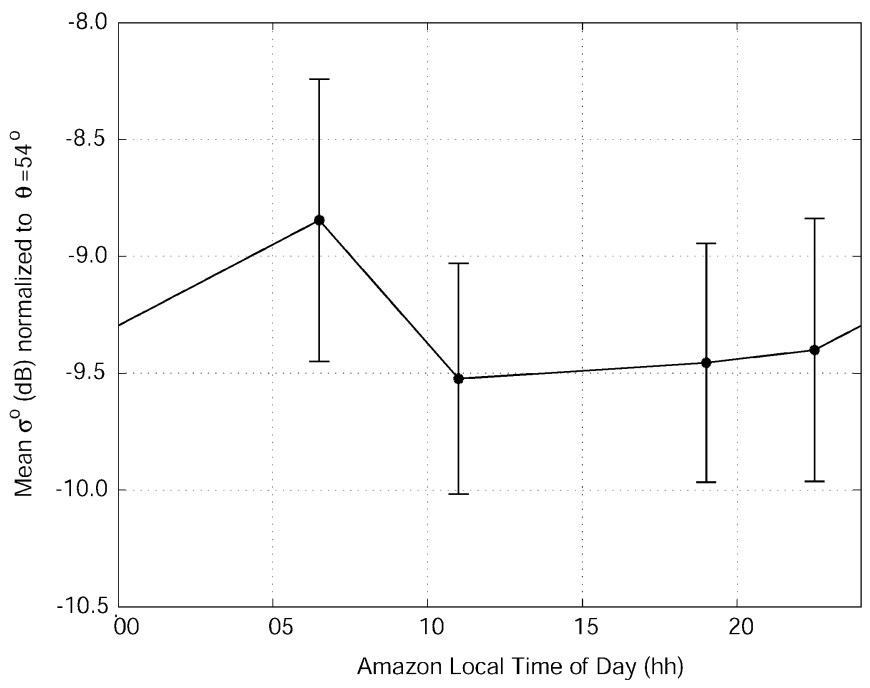

Fig. 5. Mean incidence-angle-corrected V-pol backscatter values at $54^{\circ}$ incidence angle from QuikSCAT and SeaWinds versus local time of day.

\section{B. Sahara}

Though smaller and less homogenous than the Amazon, the masked Sahara region is expected to be temporally stable over the study period with no daily moisture variation expected. The $\sigma^{o}$ measurements for this region are much noisier than for the Amazon. This is expected, since the power of the desert surface backscatter is roughly two orders of magnitude $(20 \mathrm{~dB})$ lower than for the vegetation of the rainforest, resulting in a lower signal-to-noise ratio (SNR). There is, however, no significant variation with the diurnal cycle (see Table II and Fig. 4). Averaged over time, the incidence-angle-corrected V-pol slice backscatter values for the Sahara region illustrate that the two sensors are well-calibrated. The measurements for all passes of both sensors are within $\pm 0.15 \mathrm{~dB}$. Similar results are obtained for $\mathrm{H}$-pol and for egg measurements.

The incidence angle corrected values indicate that for the spatially homogeneous Amazon area considered, the mean daily standard deviation of the measurements for each sensor is $\sim 0.5 \mathrm{~dB}$. The Sahara is less homogenous and noisier, resulting in a mean daily standard deviation of $\sim 1.8 \mathrm{~dB}$ for the Sahara. For the time-series analyzed, it is evident that for a given local time-of-day, these regions are temporally stable, since the daily mean backscatter value has a standard deviation of less than $0.18 \mathrm{~dB}$ for both regions. The nominal standard deviation of the mean backscatter and the mean daily standard deviation in the backscatter are roughly equivalent between QuikSCAT and SeaWinds.

\section{CONCLUSION}

The radar response measurements from the ascending and descending passes of the scatterometers, which occur at different local times of day, show that the Amazon rainforest exhibits diurnal variation. This large variation in $\sigma^{o}$ due to the diurnal cycle limits the ability of the method to cross-validate the calibration of the sensors at this site. However, when coupled with Sahara observations, the results indicate that the QuikSCAT and SeaWinds scatterometers are calibrated to within $\sim \pm 0.05 \mathrm{~dB}$. 


\section{ACKNOWLEDGMENT}

QuikSCAT and SeaWinds SIR image data were obtained from the Scatterometer Climate Record Pathfinder. The authors thank the anonymous reviewers for their helpful comments and suggestions. This work was completed at the Brigham Young University Microwave Earth Remote Sensing Laboratory.

\section{REFERENCES}

[1] I. J. Birrer, E. M. Bracalente, J. Sweet, and G. Berthold, " $\sigma^{\circ}$ signature of the Amazon rainforest obtained from the Seasat scatterometer," IEEE Trans. Geosci. Remote Sens., vol. GE-20, no. 1, pp. 11-17, Jan. 1982.

[2] D. G. Long and G. B. Skouson, "Calibration of spaceborne scatterometers using tropical rain forests," IEEE Trans. Geosci. Remote Sens., vol. 34, no. 2, pp. 413-424, Mar. 1996.

[3] W. Tsai, J. E. Graf, C. Winn, J. N. Huddleston, S. Dunbar, M. H. Freilich, F. J. Wentz, D. G. Long, and W. L. Jones, "Postlaunch sensor verification and calibration of the NASA Scatterometer," IEEE Trans. Geosci. Remote Sensing, vol. 37, no. 3, pp. 1517-1542, May 1999.
[4] J. Zec, D. G. Long, and W. L. Jones, "NSCAT normalized radar backscattering coefficient biases using homogenous land targets," $J$. Geophys. Res., vol. 104, no. C5, pp. 11 557-11 568, May 1999.

[5] M. Satake and H. Hanado, "Diurnal change of Amazon rain forest $\sigma^{\circ}$ observed by Ku-band spaceborne radar," IEEE Trans. Geosci. Remote Sens., vol. 42, no. 6, pp. 1127-1134, Jun. 2004.

[6] J. N. Huddleston, W.-Y. Tsai, M. W. Spencer, B. W. Stiles, and R. S. Dunbar, "SeaWinds on QuikSCAT: Postlaunch calibration and validation," in Proc. IGARSS, vol. 3, 2000, pp. 1024-1026.

[7] J. Zec, W. L. Jones, and D. G. Long, "SeaWinds beam and slice balance using data over Amazonian rainforest," in Proc. IGARSS, vol. 5, 2000, pp. 2215-2215.

[8] S. Dunbar et al., "QuikSCAT science data product user's manual," Jet Propulsion Lab., Pasadena, CA, D-18053, Oct. 1999.

[9] M. W. Spencer, C. Wu, and D. G. Long, "Improved resolution backscatter measurements with the SeaWinds pencil-beam scatterometer," IEEE Trans. Geosci. Remote Sens., vol. 38, no. 1, pp. 89-104, Jan. 2000.

[10] D. S. Early and D. G. Long, "Image reconstruction and enhanced resolution imaging from irregular samples," IEEE Trans. Geosci. Remote Sens., vol. 39, no. 2, pp. 291-302, Feb. 2001. 